\title{
Methodology for Enhancement of Energy Efficiency in Hydraulic Equipment
}

\author{
Sergio Luiz Pereira, Guilherme F. Fa. Sortino, Eduardo Mário Dias and Maria Lídia Rebello Pinho Dias \\ Department of Electrical Energy and Automation, University of Sao Paulo - Polytechnic School - Sao Paulo, Brazil
}

\begin{abstract}
The cost of energy has increased greatly in the last decades, even with technological impact attenuators, which brings a concern with the increase of production effectiveness and better use of energy by machines and advanced equipment in industrial plants. This article proposes a methodology that allows a more rational use of energy in the production environment, applying Automation Technology, which represents a more affordable approach in relation to the high capital demanding complete machine replacement by the latest highest efficiency version available. The methodology thus contribute to reducing capital consumption, reducing costs, impacting both in the productive and financial performance of the organizations, with the overall result meaning less damage to the environment, providing sustainable gains.
\end{abstract}

\section{Introduction}

The changes in the world economy in the last decades have had substantial impact on the industrial sector, as the Third Industrial Revolution, led to the modernization and automation of production processes, accelerating the manufacturing systems and allowing increase the quantity produced and the product diversification (VASCONCELLOS, 2013) [1]. Many industrial equipment, at least with regard to energy use, were kept in the same technology standard since they were created, some of which even have added new energy demands by incorporating technological innovations and new automation devices. After the 1990s, with the establishment and consolidation of the age of the New Economy and, more recently, in the age of the Information Society, it has been possible to see the genesis of an original approach, called "Ecoeconomics", whose foundations are in Pereira and Simão Filho (2014) [2], based on the proposals of Georgescu-Roegen, Herman Daly et al, originally made in the 1970s, where they show that the society and the economy are undergoing evolutionary steps, often of the organizational and technological character, which promote changes affecting the form of economic organization and also the physical equipment of industrial processes. The changes, including in the decision-making processes, have incorporated, ultimately, the notion that we seek constantly "improving the efficiency of all processes" with the economic system favoring essentially the human being (PEREIRA; SIMÃO FILHO, 2014, p. 15) [2]. Al Gore (2009) [3], for example, mentions that after the human travel into space in the $1960 \mathrm{~s}$, when the planet Earth could be seen in its entirety, it became clear the notion of planetary limited resources, to the point that the UN (United Nations) proposed since then meetings to discuss the concern with the limits of resources and respect for the environment. Thus, it is projected on the business environment, especially in the evolving Century XXI, a growing concern for ecosystems, with the limitation of production factors and energy efficiency, so that the rational use of energy passes to be seriously considered in corporate decision-making processes, first for the equipment and light and flexible machines, and then to the large industrial equipment (SCHULER, 2014) [4]. This paper presents the MAAMEES (original acronym in Brazilian Portuguese) Methodology for the Application of Automation in Large Industrial Equipment for Enhancement of Energy Efficiency and Sustainability Gains, proposing a developed solution to help the industry become more energy effective, with gains not just for the economy but above all for the whole society and the environment.

\section{Methodology for energy effectiveness}

The processes of transformation of an organization are benefited by the adoption and application of appropriate methodologies (SILVA, 2013) [5]. For the purpose of this article there is the Methodology for the Application of Automation in Large Industrial Equipment for Enhancement of Energy Efficiency and Sustainability Gains, known as MAAMEES. Sustainability Gains, know as MAAMEES. Sustainability Gains, known as MAAMEES. Sustainability Gains, known as MAAMEES. The principles of the use of MAAMEES are based on the proposal of use of AT with the objective of eliminating a 
significant percentage of the energy expended without the effective transformation into useful work that the traditional operation of large hydraulic machines perform. This means the search for the reduction of the energy expenditure in front of the total work done, meaning in practice an increase of energy efficiency. MAAMEES consists of some fundamental steps that include: i) "exante" analysis; (ii) implementation; and (iii) "ex-post" analysis. The flowchart, shown in figure 1 , is recommended for its application and allows understanding the process.

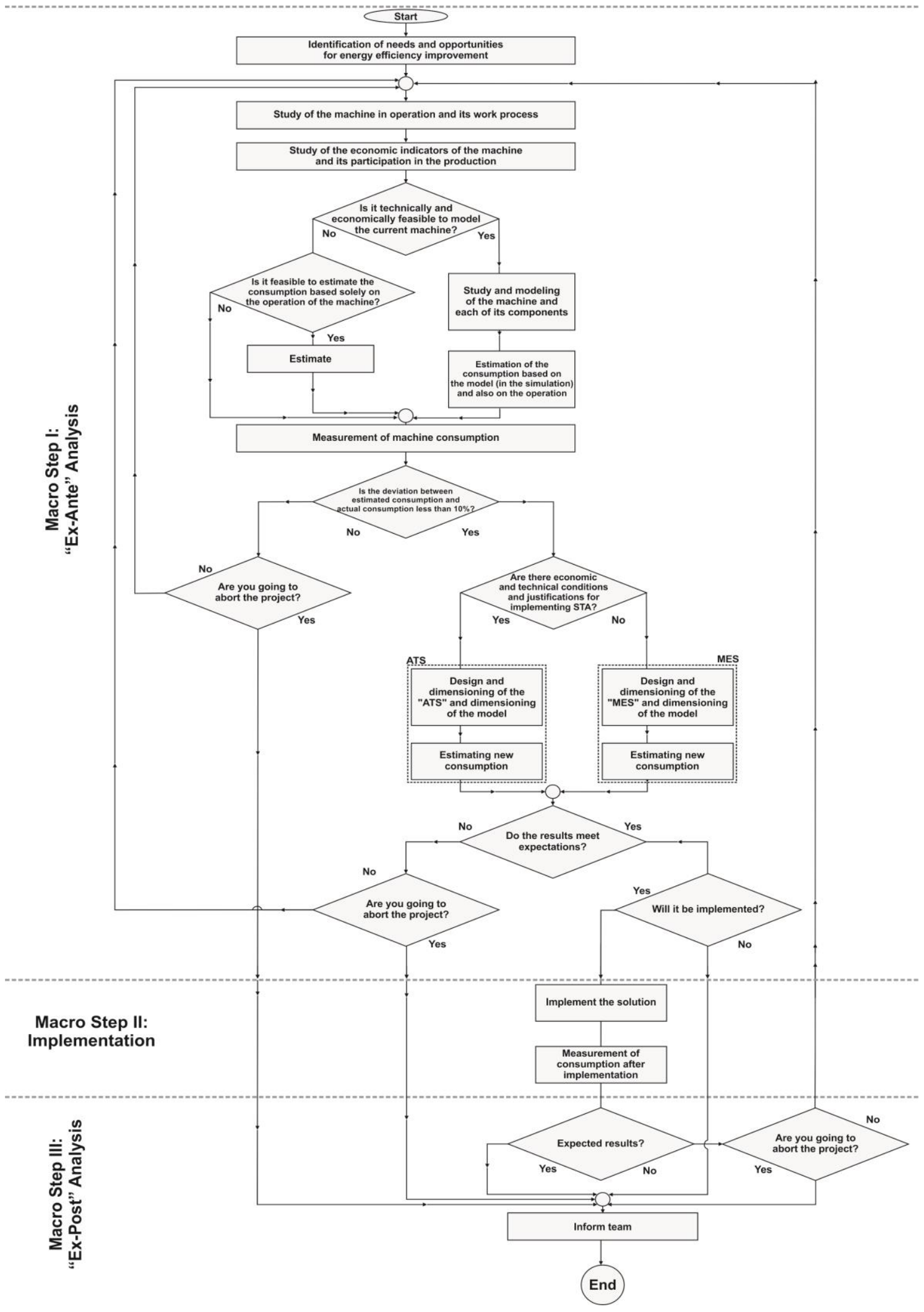

Figure 1. MAAMEES Flowchart. 
In the "ex-ante" analysis, a preliminary and detailed diagnosis should be made of the unit where the process for energy efficiency will be applied. At the same time, it is important to analyze the current situation of the company regarding the concern with the energy economy and with environmental and sustainability issues. Also, an analysis of the current contribution of the industrial unit in terms of energy economy and its degree of commitment to the environmental and sustainability issues of the company as a whole, as well as an analysis of the industrial processes and machinery and equipment used in the industrial unit regarding energy efficiency. It is important to carefully identify the equipment or machine object of the application of the methodology for energy efficiency gains. It is desirable, prior to the application of the methodology, to study in advance the environmental, technological, human and economic financial viability of the unit that will suffer the direct impact of the Methodology and resulting interventions. A diagnosis of the AT situation in the company and in the industrial sector should also be made based on corporate and sector reports that express the commitment of the company and its competitors to the use of automation for industrial production. This analysis aims to identify if the company has already assimilated and if the companies of the sector have already assimilated the latest automation technologies. Also, an analysis should be made of the situation of the company and its sectoral competitors in terms of commitments to energy efficiency and sustainability. It is advisable to identify as thoroughly as possible what actually exists and what has already been planned with a view to energy efficiency in the industrial sector of the company. It should then analyze what the existing automation produced from its adoption, thus, identifying the situation to know if the existing level of automation already contributes in some way to energy efficiency. It is also necessary to identify whether the current automation technology has impacts on the environment, human resources and other factors of interest, such as stress and noise. In this step, a survey is also made of indicators that measure the main parameters of interest, particularly the energy consumption of the process studied and the effects on production capacity. Next, it is necessary to analyze in advance the possible efficiency gains provided by the different solution alternatives that exist and that are economically feasible within the industrial, product and market conditions to which they belong. A virtual analysis is recommended through technologies of early simulation of the potential results after the changes that lead to the gain of energy efficiency are implemented. A study should be made of the investments required for the alternative that is most appropriate for the existing context, as well as anticipated studies on possible impacts and expected results, and the analysis of environmental, technological, human and economic-financial viability. If possible, the theoretical model should be used to measure a priori the energy efficiency gain for the modifications to be implemented, making the recommendations for administration as the preliminary studies indicate that the path is feasible. Once feasibility has been obtained and the necessary approvals have been obtained, the whole process of implementing the modifications chosen must be monitored, so as to ensure that they are carried out as planned. Given that the proposed changes were decided and the implementations were carried out, measurements and indicators should be collected, which will allow the analysis of the gains actually obtained in terms of energy efficiency, enabling them to be bought with the ex-ante situation. Similarly, it should be verified whether the theoretical gains in energy efficiency have been confirmed by comparing the actual results before and after the implementation of the methodology, identifying and confirming the energetic efficiency gains predicted and measured through actual results. After confirmation of the energy efficiency gains, one must also identify the gains in terms of human consumption, input savings, $\mathrm{CO} 2$ emissions, among other economic, environmental and sustainability factors.

When analyzing the initial macro phase of MAAMEES, the "Ex-Ante" Analysis, empirical situations show that there are two possibilities for the improvement of the large industrial hydraulics machines, which are called ATS (Advanced Technological Solution) and SME (Solution of Maximum Effectiveness). It is the economic analysis of the existing conditions that determines whether to adopt the ATS or SME. The ATS involves the utilization of a structural part of the equipment, performing its modernization through investments in the replacement of the pre-existing conventional hydraulic system by a modern servo motor coupled to the hydraulic pump of high precision and efficiency, which are integrated into dedicated management of processes and operations. In other words, if the hydraulic machine in question is used to produce volume that represents high added value in the production process, it is justified to use the ATS solution, which will require additional costs in the acquisition of modernization equipment and whose main suppliers currently in the world are the German companies Voith and Siemens. The ATS application results in the use of less physical volume by its components in the machine than the conventional hydraulic solution being replaced. This feature facilitates the modernization processes of equipment. The sensors used in the modernization process by ATS also favor appropriate diagnostics for the application of preventive and predictive maintenance. The SME solution, on the other hand, is indicated when the aggregate value and volume of production is not high and therefore it is not justified to make additional investments in equipment modernization assets. In this case, an update can be made to the safety device control software of the hydraulic machine, making the time the machine stays on being reduced and leading to energy efficiency gains. When adopted, the SME may have two basic architectures: when the machine already has an on-off control system managed by a programmable logic controller, no spare equipment will be needed. When the machine is old, a programmable controller has to be integrated to the drive system and position sensors must be attached. The SME solution has as principle the automatic shutdown of the hydraulic machine when it is not in production, seeking to 
take advantage of existing solutions, such as functional safety at the operation site, and it is relatively cheaper because it requires only the analysis of the production process and the machine itself, with the insertion of new logical sequences in the existing AT software. This solution takes advantage of the equipment, adding additional routines of automation through adjustment and insertion of command lines in the software that are responsible for adjusting the productive demands to the potential of reduction of consumption identified in the study of the equipment. It also improves the production process in order to ensure the operation of the hydraulic system in the minimum feasible period for the execution of the scheduled batches. This logic allows the machine equipped with the SME to remain disconnected in most of its interval periods or idleness between the processing activities of the batches produced, with a minimum of interference from the operators. When applying the MAAMEES, whether in the ATS or SME version, double direction gains are observed, since the company will benefit from the positive influence of the real EcoEconomic environment, which is also inserted in the achievement of more efficient energy indicators, as well as will be the contribution of the company to the economy as a whole, where companies from the same value chain can also benefit from the applied methodology.

\section{The empirical test of MAAMEES}

From the methodologies presented above, MAAMEES stands out for its effectiveness in achieving energy gains, first because it is relatively simple and second because it presents objective results as soon as its implementation occurs. MAAMEES was submitted to two empirical tests, the first one, using the SME (Solution of Maximum Effectiveness) version, was carried out in a hydraulic machine in the MBB Mercedes Benz do Brazil, and the second one, using the ATS (Advanced Technological Solution) version, applied to a Voith's client machine in Germany.

\section{The SME approach}

The plant has several hydraulic machines of different generations, requiring engineering decisions aimed at improving energy efficiency. The application of MAAMEES followed the steps defined in the flowchart shown in figure 1, containing the Macro Phases I, II and III, respectively "'Ex-ante' Analysis", "Implementation" and "'Ex-post' Analysis", the last two carried out by simulation. A preliminary diagnosis was made at the MBB's operational unit, where tens of presses with capacities of up to 1,300 tons, several of them hydraulic, were in operation, among them the Ciola 60t Press (manufactured in 1976), model 1C-60BA, with a $250 \mathrm{x}$ $250 \mathrm{~mm}$ table, $150 \mathrm{~mm}$ stroke, $300 \mathrm{~mm}$ opening, mono speed and two-hand trip, and modernized in 2014 to meet Brazilian safety standards. The machine was studied during a typical production week when an average of 336 pieces per day was produced, that is 168 pieces per shift or even 21 pieces per hour on average. The production made by this machine is of low value added and it would be necessary to invest approximately $€ 20.000$ for its modernization within the ATS concept of MAAMEES. The company's executives chose the simplest solution, updating the machine's operating software within the MAAMEES SME concept. During the 120 total measurement hours, the machine operated for about 80 hours, in two shifts, with the average energy consumption per hour of $2.03 \mathrm{kWh}$, producing 1,680 parts or 336 parts per day, obtaining 10.34 parts per $\mathrm{kWh}$. In terms of potential of production, the machine can produce 360 parts per hour, or 177.3 parts per $\mathrm{kWh}$, which shows that the energy efficiency measured is approximately $94 \%$ lower than it could be if the machine were fully used or if it was disconnected during the periods of non-production. The Machine is therefore used only $6 \%$ of its operating time. With the implementation of SME the machine is switched off after 90 seconds of idle operation. The process of arriving pieces is given by crates containing in average thirty pieces, with great randomness of arrival. Due to the variability of the parts arrival process, it is not possible to estimate the energy consumption accurately, thus estimating the possible energy savings based on two extremely demanding machine behaviors: scenarios A and B shown on table 1. Scenario A: Constant Request Behavior Based on Average Production. The behavior of the machine in this scenario assumes a constant ratio of the arrival rate of 21 pieces per hour, or approximately 1 piece per 171 seconds. By adopting for the purpose of this study that this behavior of the productive plant between the arrival of one piece and another is correct, there will be an interval of 171 seconds between one piece and the next one. As the proposed control algorithm commands the shutdown every 90 seconds of waiting, in this hypothetical operational situation the machine would turn off something around $40 \%$ of its normal production time. In this estimation we have already considered the stabilization times during the drive. It is important to point out, however, that this scenario is hardly feasible in the practical reality of the industry.

Table 1. Possible energy saving scenarios with SME deployment

\begin{tabular}{|c|c|c|}
\hline $\begin{array}{c}\text { SME } \\
\text { Implementation }\end{array}$ & $\begin{array}{c}\text { Reduction of } \\
\text { Energy } \\
\text { Consumption }\end{array}$ & $\begin{array}{c}\text { Economy in KWh } \\
\text { (Average per } \\
\text { Hour) }\end{array}$ \\
\hline Scenery A & $40 \%$ & 0,81 \\
Scenery B & $94 \%$ & 1,91 \\
\hline
\end{tabular}

Scenario B: Behavior of Requests with the Arrival of the Whole Lot with the Full Volume of the Daily Schedule. In this scenario it is considered that 336 pieces arrive at almost the same time. In this way, a queue is formed where the pieces are processed one after the other. As the machine capacity is 360 parts per hour, that is, 10 seconds per piece, it will take 3,360 seconds or 56 minutes of operation for the production of all 336 pieces. In this way the machine would only be turned on for about 1 hour from the 16 hours of the two shifts. That is, only $6.25 \%$ of the production time would be connected. If the total consumption of the machine every two shifts is 
$32.5 \mathrm{kWh}$, the estimated hourly consumption in this case would be $2.03 \mathrm{kWh}$. Thus, considering scenario A and scenario $\mathrm{B}$, the range of consumption reduction would be between $40 \%$ and $93.75 \%$. Table 2 illustrates the energy gain data for the two scenarios with SME deployment. It should be noted that the expected results for the two cases are very satisfactory, so that the executives responsible for decision making process in the company have opted definitively for the implementation of SME. The company considered the results very important, so that this engineering project was adopted by the organization's energy efficiency schedule. Initially, the machine demanded almost 7.9 MWh per year in its operation, at a cost of more than $\mathrm{R} \$ 3,173.00$, but with the application of MAAMEES and particularly its SME approach, it was possible to reduce this energy consumption to only 0.79 MWh per year, providing a monetary savings in the order of more than R $\$ 2,856.00$ for one machine only. From an investment of just over $\mathrm{R} \$ 4,600.00$ the company obtained in terms of reduction of energy consumption a cost savings of more than $\mathrm{R} \$ 2,856.00$ per year for a machine with a useful life of more than 10 years.

Table 2. Actual and simulated results on the studied machine

\begin{tabular}{lccc}
$\begin{array}{c}\text { Results for the } \\
\text { Studied Machine }\end{array}$ & $\begin{array}{c}\text { Energy Consumption } \\
\text { in } \mathbf{3 6 5} \text { days (MWh) }\end{array}$ & $\begin{array}{c}\text { Annual Energy } \\
\text { Cost (R\$) }\end{array}$ & $\begin{array}{c}\text { Savings } \\
\text { (R\$) }\end{array}$ \\
Situation ex-ante & 7,86 & $3.173,87$ & - \\
Situation ex-post & 0,786 & 317,39 & $2.856,48$ \\
\hline
\end{tabular}

With this data it is possible to carry out the economic viability analysis of the implementation of SME in one or more similar machines. For this purpose, the methods of valuation Payback Period, Net Present Value and Internal Rate of Return will be used. In the calculus was considered the interest rate published by the Central Bank of Brazil for February/2017, which stood at $13 \%$ per year. By making a linear extension of the result found in the simulation for one machine, it was possible to already see from five machines that the company has its costs with the SME diluted and it obtain a positive and continuously increasing net result. Applying SME to five similar machines, the company obtains a gain of $\mathrm{R} \$ 7.7$ thousand per year, which reaches more than $\mathrm{R} \$ 243$ thousand when extending the application of SME to 100 similar hydraulic machines.

Table 3. Income statement for simulated scenarios

\begin{tabular}{|c|r|l|c|c|c|}
\hline \multicolumn{2}{|c|}{ Scenery } & $\begin{array}{c}\text { Annual } \\
\text { Revenue }\end{array}$ & Cost & Net Result \\
\hline 1 & 1 & conventional hydraulic machine & $\mathrm{R} \$ 2.856,48$ & $\mathrm{R} \$ 4.468,25$ & $-\mathrm{R} \$ 1.831,77$ \\
2 & 5 & similar machines & $\mathrm{R} \$ 14.282,41$ & $\mathrm{R} \$ 6.563,55$ & $\mathrm{R} \$ 7.718,86$ \\
3 & 10 & similar machines & $\mathrm{R} \$ 28.564,81$ & $\mathrm{R} \$ 8.438,85$ & $\mathrm{R} \$ 20.125,96$ \\
4 & 50 & similar machines & $\mathrm{R} \$ 142,824,06$ & $\mathrm{R} \$ 23.441,25$ & $\mathrm{R} \$ 119.382,81$ \\
5 & 100 & similar machines & $\mathrm{R} \$ 285.648,12$ & $\mathrm{R} \$ 42.194,25$ & $\mathrm{R} \$ 243.453,87$ \\
\hline
\end{tabular}

For the "Payback Period" method, both inflation and interest rates are of no importance, since the analysis is only nominal, and it shows how long the company can recover the investment made in the application of the SME. In table 4 it is possible to see that the resources used in only one machine would take almost 20 months to be recovered, but for 5 machines the time of recovery of the investment falls to less than 6 months, showing full feasibility in the application of SME from the point of view of the Payback method. It is important to note that in the scenario where SME is applied for a park of 100 similar hydraulic machines, the Payback Period is reduced dramatically to less than two months.

In table 5 it is possible to see the nominal cash flow for a period of five years, applied to each of the five scenarios defined. The application of the SME to only one machine already presents a positive Net Present Value (in an economy with a $13 \%$ annual interest rate) and an
Internal Rate of Return of $54 \%$ a year, which shows the full feasibility for its implementation, under the conditions considered in the simulation.

Table 4. Viability analysis by payback period

\begin{tabular}{|c|c|c|}
\hline \multirow{2}{*}{ Scenery } & \multicolumn{2}{|c|}{ Payback Period } \\
\cline { 2 - 3 } & Month & Year \\
\hline $\mathbf{1}$ & 19,7 & 1,64 \\
$\mathbf{2}$ & 5,51 & 0,46 \\
$\mathbf{3}$ & 3,55 & 0,30 \\
$\mathbf{4}$ & 1,97 & 0,16 \\
$\mathbf{5}$ & 1,77 & 0,15 \\
\hline
\end{tabular}


Table 5. Simulated cash flows, NPV and IRR results

\begin{tabular}{|c|c|c|c|c|c|c|c|c|c|}
\hline Scenery & N.P.V. & I.R.R. & Machines & 0 & 1 & 2 & 3 & 4 & 5 \\
\hline 1 & $\mathrm{R} \$ 4.742,17$ & $54 \%$ & 1 & $-\mathrm{R} \$ 4.688,25$ & $\mathrm{R} \$ 2.856,48$ & $\mathrm{R} \$ 2.856,48$ & $\mathrm{R} \$ 2.856,48$ & $\mathrm{R} \$ 2.856,48$ & $\mathrm{R} \$ 2.856,48$ \\
\hline 2 & $\mathrm{R} \$ 64.848,48$ & $217 \%$ & 5 & $-R \$ 6.563,55$ & $\mathrm{R} \$ 14.282,41$ & $\mathrm{R} \$ 14.282,41$ & $\mathrm{R} \$ 14.282,41$ & $\mathrm{R} \$ 14.282,41$ & $\mathrm{R} \$ 14.282,41$ \\
\hline 3 & $\mathrm{R} \$ 134.385,21$ & $338 \%$ & 10 & $-R \$ 8.438,85$ & $\mathrm{R} \$ 28.564,81$ & $\mathrm{R} \$ 28.564,81$ & $\mathrm{R} \$ 28.564,81$ & $\mathrm{R} \$ 28.564,81$ & $\mathrm{R} \$ 28.564,81$ \\
\hline 4 & $\mathrm{R} \$ 690.679,05$ & $609 \%$ & 50 & $\mathrm{R} \$ 23.441,25$ & $R \$ 142.824,06$ & $R \$ 142.824,06$ & $R \$ 142.824,06$ & $R \$ 142.824,06$ & $R \$ 142.824,06$ \\
\hline 5 & $\mathrm{R} \$ 1.386 .046,35$ & $677 \%$ & 100 & $\mathrm{R} \$ 42.194,25$ & $\mathrm{R} \$ 285.648,12$ & $\mathrm{R} \$ 285.648,12$ & $\mathrm{R} \$ 285.648,12$ & $\mathrm{R} \$ 285.648,12$ & $\mathrm{R} \$ 285.648,12$ \\
\hline
\end{tabular}

When the application of the SME for each of the five scenarios is extended, the situation improves significantly, with the NPV reaching almost $\mathrm{R} \$ 1.4$ million for the case of 100 machines and IRR of $677 \%$ per year. The results obtained prove that the application of the SME is feasible not only for a machine but for different scenarios where it would be applied to a huge number of similar hydraulic equipment in the industrial plant.

\section{The ATS approach}

The application of MAAMEES in its ATS (Advanced Technological Solution) version was done by simulation in an industrial plant of a Voith's client in Germany, where a $4,000 \mathrm{kN}$ press was chosen. The hydraulic press is allocated to produce parts of three different types of products: A-type parts, B-type parts and C-type parts. The constructive details and operational characteristics of the three types of parts were not considered relevant for the empirical test. However, it is known that the piece of type A demands 9.33 seconds to be produced, the piece of type $\mathrm{B}$ demands 4.5 seconds and the part of type $\mathrm{C}$ demands 9.0 seconds, according to table 6 .

Table 6. Nominal capacity in time by type of parts

\begin{tabular}{|c|c|c|c|c|c|}
\hline $\begin{array}{c}\text { Period } \\
\text { Type of parts }\end{array}$ & Hour & 8 hs shift & Day/3 shifts & Week/5 work days & $\begin{array}{c}\text { Year/50 work } \\
\text { weeks }\end{array}$ \\
\hline A & 385 & 3.080 & 9.240 & 46.200 & 2.310 .000 \\
B & 800 & 6.400 & 19.200 & 96.000 & 4.800 .000 \\
C & 400 & 3.200 & 9.600 & 48.000 & 2.400 .000 \\
\hline
\end{tabular}

Source: Adapted from Voith (2017) [6]

The productions for the year 2016 of the three pieces, type A, type B and type C, were respectively: 577,500; $1,200,000$ and 600,000 units of each type. It is known that the average energy demand of this hydraulic machine is $11 \mathrm{~kW}$ continuously. During the data collection period the machine was running three shifts a day, i.e. the machine remained on 24 hours a day and 120 hours a week. It was observed that, regardless of the type of part produced, the weekly consumption was $1,320 \mathrm{kWh}$, meaning that the press consumed $264 \mathrm{kWh}$ per day, $88 \mathrm{kWh}$ per shift or 11 $\mathrm{kWh}$ per hour. These measurements were carried out throughout 2016 when the machine energy annual consumption was $66,000 \mathrm{kWh}$. Production and energy consumption data indicate three productivity indices: 8.8 pieces per $\mathrm{kWh}$ for Type A parts, 18.2 pieces per $\mathrm{kWh}$ for Type B parts and 9.1 pieces per $\mathrm{kWh}$ for type C. Although the press was operating at $100 \%$ of its operational capacity, the energy indicators would be: 35 pieces per $\mathrm{kWh}, 72.7$ pieces per $\mathrm{kWh}$ and 36.4 pieces per $\mathrm{kWh}$, respectively. This shows that the energy efficiency of this press for the three types of parts is around $25 \%$. In the case of the Voith customer machine in Germany the volume of production and the value added of the production is undoubtedly bigger than in the case of the press studied at MBB. So the control routine that shuts off the machine when the time between parts is bigger than 90 seconds does not meet the expectations of reduction of energy consumption. Due to the high volume of parts produced by the press and its added value, the project management team opted to apply the MAAMEES in its ATS version. With the application of ATS, the press, when connected, works only in its electronic part, remaining with the step motor inactive until it is activated by the operator when executing an operation of pressing. The motor shuts off as soon as the operation is completed, with only the electronic part of the machine switched on until a new part is positioned and the process is started again by the operator. With the implementation of ATS, the press request by the planning and production control sector remains the same. However, the electrical power demanded by the stepper motor is only observed at the actual moment of the mechanical work of the press. The total cycle analysis allows the conclusion that the pressing, stamping and pressure retention times correspond on average to $15 \%$ of the time of a pressing cycle considering the usual waiting times. These times vary 
according to the requests of each piece. Thus there is an energy saving space if the stepper motor only operates at the times of effective work. As the times vary greatly and as the machine with ATS stays on, there is no possibility to estimate the very precise consumption reduction. However, it is possible to assume that the estimated reduction of energy consumption should be between $60 \%$ and $80 \%$. As the consumption reduction data were very favorable throughout the project, the management group decided that the ATS alternative should be implemented. The ATS was put into operation and it was checked whether the mechanical performance for the production of parts remained the same. A strict quality control and compliance with the new parts produced were also carried out. Once the ATS alternative was approved from an operational point of view, the electric consumption meter was re-installed to carry out new measurements and the comparison between estimated consumption and actual consumption. These measurements were carried out during a month in the first half of 2017 and the data of the new consumption are shown in table 7.

Table 7. Energy efficiency results with ATS application

\begin{tabular}{|c|c|c|}
\hline Parts type & $\begin{array}{c}\text { Energy } \\
\text { Consumption }\end{array}$ & Reduction \\
\hline A & $1.350 \mathrm{kWh}$ & $75 \%$ \\
B & $800 \mathrm{kWh}$ & $86 \%$ \\
C & $1.367 \mathrm{kWh}$ & $76 \%$ \\
\hline
\end{tabular}

Source: Adapted from Voith (2017) [6]

It should be noted that the consumption reduction was within the expected range, with $75 \%$ for part $\mathrm{A}, 86 \%$ for part B and $76 \%$ for part C. The monthly volume of production during the measurements was practically the same and energy efficiency of the press with the ATS has achieved significant gains, going to, in the case of part $\mathrm{A}$ to 35 parts per $\mathrm{kWh}$, for part $\mathrm{B}, 73$ pieces per $\mathrm{kWh}$ and for part $\mathrm{C}$ was 36 pieces per $\mathrm{kWh}$. The original conditions considered for calculating the energy efficiency improvement of this press while operating with its conventional hydraulics is approximately $11 \mathrm{~kW}$ continuously. In addition, the following working parameters are considered: three shifts, five working days per week and 50 weeks per year. ATS's application resulted in the average energy cost per unit produced in the operation for cycle 1 of $€ 0.54$, for cycle 2 of $€ 0.32$ and for cycle 3 of $€ 0.52$.

The organization's expectations that MAAMEES could contribute to the reduction of the average operating cost of energy, while preserving the production volumes unchanged, have been confirmed since the hydraulic machine in its conventional configuration results in an annual energy consumption of $66,000 \mathrm{kWh}$, which represents an annual cost of $€ 13,200.00$.
Table 8. Results of energy consumption, cost reduction and payback with ATS application

\begin{tabular}{|c|c|c|c|}
\hline $\begin{array}{c}\text { Parts } \\
\text { type }\end{array}$ & $\begin{array}{c}\text { Annual Energy } \\
\text { Consumption }\end{array}$ & $\begin{array}{c}\text { Annual } \\
\text { Saving }\end{array}$ & $\begin{array}{c}\text { Payback } \\
\text { period }\end{array}$ \\
\hline A & $16.200 \mathrm{kWh}$ & $€ 9.960$ & 1,75 years \\
B & $9.600 \mathrm{kWh}$ & $€ 11.280$ & 1,5 years \\
C & $15.600 \mathrm{kWh}$ & $€ 10.080$ & 1,7 years \\
\hline
\end{tabular}

Source: Voith (2017) [6]

As can be seen in table 8, the application of MAAMEES in the ATS version led to a reduction of costs for all parts studied, with an annual energy saving of $€ 9,960, € 11,280$ and $€ 10,080$ respectively for type A, B and $\mathrm{C}$. The original calculations, on a per-piece basis, showed that these cost reductions give the company a Payback Period, facing investments made versus realized gains, of 1.75 year for the manufacture of A-type parts, of 1.5 year to manufacturing of B-type parts, and 1.7 year for the manufacture of C-type parts. These Payback results are significant and prove, in principle, the viability of the ATS application. However, the team of engineers who conducted the project decided to apply a scenario analysis similar to that used in the experience with SME at $\mathrm{MBB}$, allowing an economic view on the application of the methodology when it extends to industrial parks that have many hydraulic presses similar in operation. The cost of implementing of the ATS solution for a single machine is $€ 17,172.00$ and when a simple results analysis is performed for a single machine, this investment is compared with an average annual revenue (calculated by the weighted average of the annual savings shown in table 10) of $€ 10,331.00$, which can give the impression that the company would suffer losses, as the economic result would be negative ( $€ 17,172.00$ is invested and a gain of $€ 10,331.00$ is obtained, with a loss of $€ 6,841.00$ ) However, the economic analysis must take into account the time, requiring the use of cash flows, since the machine will receive investments and will continue to work for a long time - and not just for a single year. Conservatively, for example, both the SME and the ATS have been studied for a 5-year planning horizon, although in many cases, due to the effectiveness of the industry maintenance programs, the hydraulic presses can operate several years and even decades. Another relevant aspect to be specifically considered in the case of the ATS application is the fact that new equipment from an external manufacturer is purchased to modernize the existing hydraulic machines. In the case of SME, only to counter, investments occur in existing software, not involving the acquisition of additional equipment from external manufacturers. This means that by applying to ATS, it is possible to negotiate discounts on the price paid for the equipment when the company wants to modernize 5,10 or 50 hydraulic machines of a certain industrial park. The ATS application engineers consulted the equipment manufacturer and obtained the results summarized in Table 9, with staggered discounts for the application of ATS in increasing numbers of machines. 
Table 9. Scenarios, revenues and investments for ATS application

\begin{tabular}{|c|r|l|r|r|}
\hline \multicolumn{2}{|c|}{ Scenery } & Annual Revenue & \multicolumn{1}{c|}{ Investment } \\
\hline $\mathbf{1}$ & $\mathbf{1}$ & Conventional hydraulic machine & $€ 10,311.30$ & $€ 17,162.00$ \\
$\mathbf{3}$ & $\mathbf{5}$ & Similar machines & $€ 51,556.52$ & $€ 81,519.50$ \\
$\mathbf{4}$ & $\mathbf{1 0}$ & Similar machines & $€ 103,113.04$ & $€ 157,890.40$ \\
$\mathbf{5}$ & $\mathbf{5 0}$ & Similar machines & $€ 515,565.22$ & $€ 772,290.00$ \\
& $\mathbf{1 0 0}$ & Similar machines & $€ 1,031,130.43$ & $€ 1,458,770.00$ \\
\hline
\end{tabular}

It should be noted that the value of the investments does not increase linearly, since the manufacturer may grant discounts for the acquisition of different numbers of equipment for the application of the ATS. The annual revenue, however, calculated by the weighted average presented in Table 10, increases linearly, since it is the direct technological result of the application of the
MAAMEES in the equipment studied. The cash flows for the five scenarios studied can be seen in Table 11, where the investments occur at the initial moment (year zero) and the results are accounted for at the end of each year. With these values it is possible to calculate the economic indicators that show if the application of ATS in the different scenarios will be viable.

Table 10. Cash Flows for ATS application in different scenarios

\begin{tabular}{|c|c|c|c|c|c|c|c|}
\hline \multirow[b]{2}{*}{ Scenery } & \multirow[b]{2}{*}{$\begin{array}{l}\text { Number of } \\
\text { machines }\end{array}$} & \multicolumn{6}{|c|}{ Year and value in $€$} \\
\hline & & 0 & 1 & 2 & 3 & 4 & 5 \\
\hline 1 & 1 & $17,162.00$ & $10,311.30$ & $10,311.30$ & $10,311.30$ & $10,311.30$ & $10,311.30$ \\
\hline 2 & 5 & $81,519.50$ & $51,556.52$ & $51,556.52$ & $51,556.52$ & $51,556.52$ & $51,556.52$ \\
\hline 3 & 10 & $157,890.40$ & $103,113.04$ & $103,113.04$ & $103,113.04$ & $103,113.04$ & $103,113.04$ \\
\hline 4 & 50 & $772,290.00$ & $515,565.22$ & $515,565.22$ & $515,565.22$ & $515,565.22$ & $515,565.22$ \\
\hline 5 & 100 & $1,458,770.00$ & $1,031,130.43$ & $1,031,130.43$ & $1,031,130.43$ & $1,031,130.43$ & $1,031,130.43$ \\
\hline
\end{tabular}

One of the first indicators calculated by the team of engineers accompanying the ATS project in Germany was the Payback Period, now considering the various scenarios, as shown in Table 11.

Table 11. Payback for the different ATS application scenarios

\begin{tabular}{|c|c|c|}
\hline Scenery & $\begin{array}{c}\text { Number of } \\
\text { machines }\end{array}$ & $\begin{array}{c}\text { Payback } \\
\text { (years) }\end{array}$ \\
\hline $\mathbf{1}$ & 1 & 1,66 \\
$\mathbf{2}$ & 5 & 1,58 \\
$\mathbf{3}$ & 10 & 1,53 \\
$\mathbf{4}$ & 50 & 1,50 \\
$\mathbf{5}$ & 100 & 1,41 \\
\hline
\end{tabular}

The observed Payback indicators closely approximate the values presented previously, in the aggregate analysis, without considering scenarios, which also showed feasibility with the return of the investment occurring approximately 1.5 years after the beginning of the application of the ATS methodology. The engineering team, however, also calculated the indicators of Net Present Value and Internal Rate of Return, as can be seen in Table 15, completing the feasibility analysis. Specialized websites in Europe clarify that interest rates in Europe are still very close to zero, but in everyday business practice it is necessary to use an opportunity cost between "investing" and "lending" money at the current maximum rate, hence why the companies use $5.30 \%$ per annum as interest rate to calculate the feasibility indicators (see www.tradingeconomics.com/euroarea/interestrate). The ATS project engineers used this rate to determine the results presented in Table 12, where it can be seen that, even for just one machine, the ATS application is already feasible, generating a net return of more than $€ 25,000$, within a 5 year analysis horizon. The same is true for a larger number of machines in the different scenarios, for example NPV of $€ 270$ thousand generated for the application of ATS to 10 machines and NPV of $€ 2.82$ million for the case of an industrial park of 100 machines.

According to the NPV criterion, as it was already the case with Payback, the ATS's economic and financial viability is already fully demonstrated. With the Internal Rate of Return calculation, the engineers show that the implicit return on operations (53\% to $65 \%$ per annum) is well above the rate of opportunity cost in the Euro Zone (5.30\% per year), completing the viability. 
Table 12. NPV and IRR for the different ATS application scenarios

\begin{tabular}{|c|c|c|c|}
\hline Scenery & Number of machines & $\begin{array}{c}\text { Net Present Value } \\
(€)\end{array}$ & $\begin{array}{c}\text { Interest Return Rate } \\
\text { (\% per year) }\end{array}$ \\
\hline $\mathbf{1}$ & 1 & $€ 25,748.10$ & $53 \%$ \\
$\mathbf{2}$ & 5 & $€ 132,815.04$ & $57 \%$ \\
$\mathbf{3}$ & 10 & $€ 270,519.55$ & $59 \%$ \\
$\mathbf{4}$ & 50 & $€ 1,368,895.93$ & $60 \%$ \\
$\mathbf{5}$ & 100 & $€ 2,819,282.84$ & $65 \%$ \\
\hline
\end{tabular}

\section{References}

1. VASCONCELLOS, M.A. S. Economia: micro e macro. São Paulo: Atlas, 2013.

2. PEREIRA, S. L.; SIMÃO FILHO, A. A Empresa Ética em Ambiente Econeconômico: a contribuição da empresa e da tecnologia da automação para um desenvolvimento sustentável inclusivo. São Paulo, Quatier Latin, 2014.

3. GORE, A. Our Choice: how we can solve the climate crisis. New York: Bloomsbury, 2009.
4. SCHULER, A. G. Energy optimization for press systems. Berlin: Powersave, 2014.

5. SILVA, E. B. Metodologia para Planejamento da Convergência da Tecnologia da Informação (TI) \& Tecnologia da Automação (TA) em Processos Industriais. Tese de doutorado. São Paulo: Escola Politécnica da Universidade de São Paulo, 2013.

6. VOITH TURBO H + L HYDRAULIC GMBH \& CO. KG. PSH Press Drive Servo Hybrid: servo pump drive system for hydraulic presses. Rutesheim, 2017. 